\title{
Porphyrin-magnetite nanoconjugates for biological imaging
}

Małgorzata Nowostawska ${ }^{1,2}$, Serena A Corr ${ }^{3}$, Stephen J Byrne ${ }^{1 *}$, Jennifer Conroy², Yuri Volkov² and Yurii K Gun'ko ${ }^{\text {* }^{*}}$

\begin{abstract}
Background: The use of silica coated magnetic nanoparticles as contrast agents has resulted in the production of highly stable, non-toxic solutions that can be manipulated via an external magnetic field. As a result, the interaction of these nanocomposites with cells is of vital importance in understanding their behaviour and biocompatibility. Here we report the preparation, characterisation and potential application of new "two-in-one" magnetic fluorescent nanocomposites composed of silica-coated magnetite nanoparticles covalently linked to a porphyrin moiety.
\end{abstract}

Method: The experiments were performed by administering porphyrin functionalised silica-coated magnetite nanoparticles to THP-1 cells, a human acute monocytic leukaemia cell line. Cells were cultured in RPMI 1640 medium with 25 mM HEPES supplemented with heat-inactivated foetal bovine serum (FBS).

Results: We have synthesised, characterised and analysed in vitro, a new multimodal (magnetic and fluorescent) porphyrin magnetic nanoparticle composite (PMNC). Initial co-incubation experiments performed with THP-1 macrophage cells were promising; however the PMNC photobleached under confocal microscopy study. $\beta$ mercaptoethanol ( $\beta-M E)$ was employed to counteract this problem and resulted not only in enhanced fluorescence emission, but also allowed for elongated imaging and increased exposure times of the PMNC in a cellular environment.

Conclusion: Our experiments have demonstrated that $\beta$-ME visibly enhances the emission intensity. No deleterious effects to the cells were witnessed upon co-incubation with $\beta$-ME alone and no increases in background fluorescence were recorded. These results should present an interest for further development of in vitro biological imaging techniques.

\section{Background}

Magnetic nanoparticles have been the focus of much research due to their potential biomedical applications as both diagnostic tools and therapeutic agents $[1,2]$. Suspensions of superparamagnetic nanoparticles of iron oxide are promising magnetic resonance imaging contrast agents, improving the image quality of anatomical structures by altering the relaxation time of the protons present [3-6]. Magnetic nanoparticles may also induce heat once subjected to an external magnetic AC field, opening up the possibility of hyperthermic cancer treatment $[7,8]$. Site-specific drug delivery is an enticing possibility, which may be realised by loading nano-magnetic carriers with therapeutic agents and

\footnotetext{
* Correspondence: sbyrne3@tcd.ie; igounko@tcd.ie

'School of Chemistry, Trinity College Dublin, College Green, Dublin 2, Ireland Full list of author information is available at the end of the article
}

directing them to the site of interest using external magnetic fields $[9,10]$. The assembly of a number of building blocks with different functionalities could provide a multimodal platform allowing for the combination of diagnostic imaging and therapeutic capabilities [11-13]. In particular, nanoscale entities combining magnetic and fluorescent properties have attracted much attention. Their potential uses in medicine are far-reaching including in imaging, bio- and chemosensing, drug delivery and therapy systems. Challenges remain in their fabrication, which frequently involve multi-step reactions to prevent the quenching of the fluorophore. Several synthetic routes have been reported, including core-shell composites, bilipid layers between the particle surface and the fluorescent moiety composites, and use of electrostatic interactions between stabilizers, magnetic particles and

\section{() Biomed Central}


fluorophores [14-18]. The surface chemistry of these composite materials plays a crucial role in cellular uptake. For example magnetic nanoparticles, functionalised with a chitosan-labelled fluorescein isothiocyanate derivative, have shown uptake by human hepatoma cells via charged interactions [19]. Interesting multifunctional nanocomposites comprising of silver and iron oxide nanoparticles embedded in a silica shell, together with a Raman reporter molecule have been published by Murphy et. al. [20]. The introduction of a rhodamine moiety to the silica surface gives the composite a broad range of potential applications due to its magnetic, light scattering, SERS and fluorescent properties. Trapping a rhodamine dye within a silica matrix during the formation of a shell surrounding the magnetite nanoparticles has also led to the formation of magnetic-fluorescent nanocomposites [21,22]. In addition superparamagnetic iron oxide nanoparticles (SPION) are of particular interest for targeted cancer therapy. Tumour-targeted hyperthermia using superparamagnetic, biocompatible, and nanosized delivery vehicles would allow patients to receive increased treatment dosages while minimizing side effects. Some recent research investigating SPION was also dedicated to the early detection of cancer, diabetes, and atherosclerosis [23-25].

Here we report the preparation, characterisation and application of new "two-in-one" magnetic-fluorescent nanocomposites composed of silica-coated magnetite nanoparticles, which are covalently linked to a porphyrin moiety.

\section{Results and discussion}

Synthesis and characterisation of the porphyrinmagnetite nanocomposite (PMNC)

Magnetite nanoparticles have been produced by a previously reported co-precipitation method (see Materials and Methods) [26,27]. Application of a silica layer was achieved by following a method reported by Philips and co-workers [28]. Briefly, a colloidal solution of magnetite nanoparticles in tetramethylammonium hydroxide (TMAH) was treated with sodium silicate in order to deposit a thin layer of silica on the surface of the oxide particles (Figure 1). In a separate step, a carboxylic acid protoporphyrin (protoporphyrin IX) was reacted with 3aminopropyltriethoxysilane (3-APTES) under inert conditions in the presence of the carbodiimide coupling agent (EDCI) to form an amide bond. This modified porphyrin was then reacted with the silica coated particles, to form a stable colloidal suspension. In this case the silica shell was necessary to provide an effective barrier between the particle core and the fluorescent porphyrin, preventing the risk of quenching.

Elemental analysis of the PMNC shows a content of $\mathrm{C}$ - 9.31, H - 1.21 and N - 1.51\%. This clearly confirms the presence of conjugated porphyrin molecules at the surface of nanoparticles.

The presence of the porphyrin on the surface of the silica-coated magnetite nanoparticles was also confirmed by Fourier Transform Infrared Infra-red (FTIR) spectroscopy (Figure 2). FTIR spectra of the silica coated magnetite nanoparticles before and after reaction with the protoporphyrin were recorded in $\mathrm{KBr}$. The silica coated

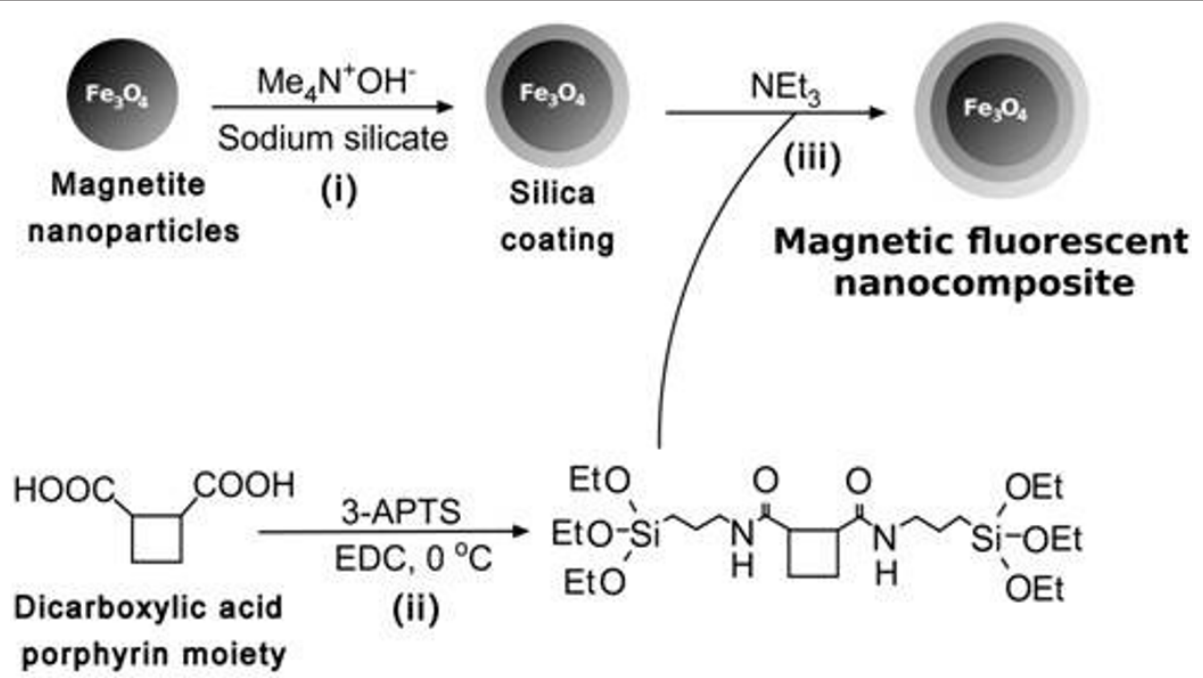

Figure 1 PMNC synthesis: Preparation of the PMNC using a base catalyzed condensation reaction to attach a 3-APTS modified protoporphyrin IX to silica coated magnetite nanoparticles. (i) A thin silica layer is introduced on the magnetite nanoparticle surface by employing TMAH and sodium silicate. (ii) An amide coupling reaction is performed between the carboxylic acid groups of protoporphyrin IX and 3-APTS. (iii) A base catalysed hydrolysis between the modified porphyrin and the silica coated magnetite nanoparticles results in a magneticfluorescent nanocomposite. 


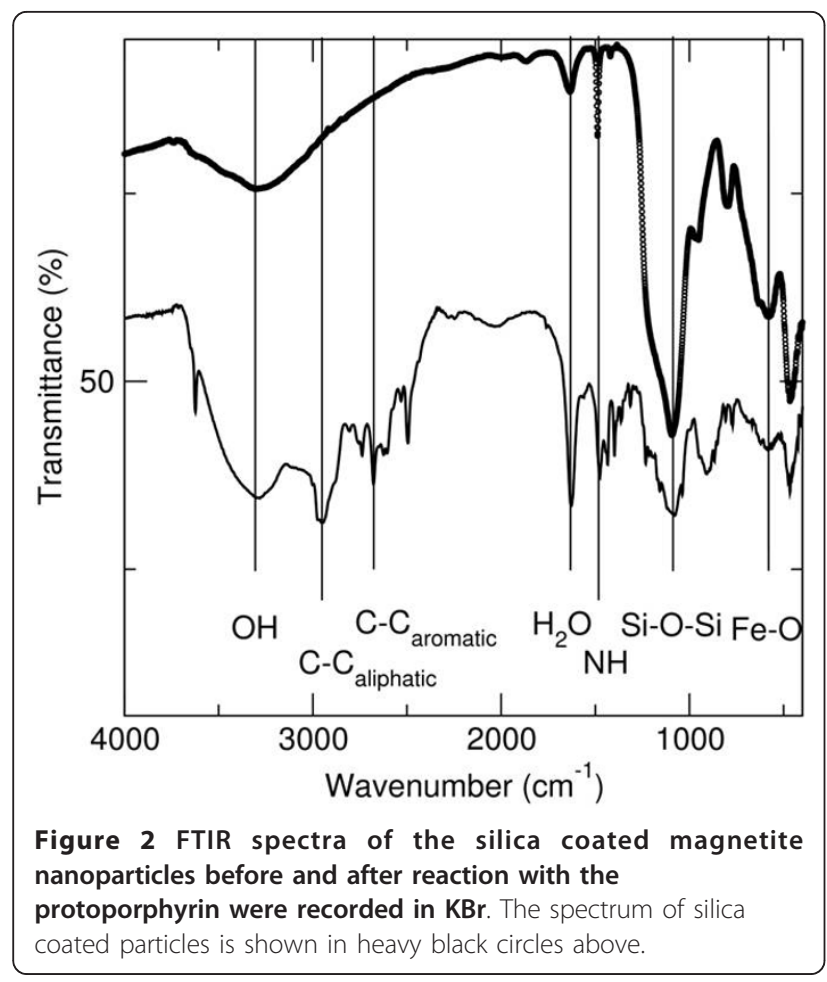

particles (shown in heavy black circles above) have stretches at 579, 1087, 1625 and $3286 \mathrm{~cm}^{-1}$ corresponding to the $\mathrm{Fe}-\mathrm{O}, \mathrm{Si}-\mathrm{O}-\mathrm{Si}$, and water stretches respectively. The stretch found at $947 \mathrm{~cm}^{-1}$ is due to the presence of Fe-O-Si bonds in the sample. For the nanocomposite material, again $\mathrm{Fe}-\mathrm{O}$ and water stretches are found at 579, 1621 and $3286 \mathrm{~cm}^{-1}$ respectively. The Fe$\mathrm{O}-\mathrm{Si}$ stretch is this time masked by the $\mathrm{NH}$ wagging from the porphyrin centred at $901 \mathrm{~cm}^{-1}$. NH stretches are found at $1473 \mathrm{~cm}^{-1}$. Aromatic and aliphatic stretches associated with the porphyrin are found at 2500 and $2945 \mathrm{~cm}^{-1}$ respectively. FTIR spectra (Figure 2) of the porphyrin nanocomposite material showed stretches for $\mathrm{NH}$ due to the presence of the porphyrin at 901 and $1473 \mathrm{~cm}^{-1}$. Aromatic and aliphatic stretches associated with the porphyrin are found at 2500 and $2945 \mathrm{~cm}^{-1}$ respectively. A core-shell-like morphology is apparent from TEM images taken of the silica coated nanoparticles. The average primary particle size is calculated to be $9.3 \pm 1 \mathrm{~nm}$. The silica coating on the particles has an average thickness of $3 \mathrm{~nm}$, however upon reaction with the 3-APTES modified protoporphyrin IX, the coating thickness is found to slightly increase to $4 \mathrm{~nm}$.

Absorbance spectra of the original porphyrin and the PMNC were taken in tetrahydrofuran, THF (Figure 3). Peaks at 406, 505, 538, 577 and $632 \mathrm{~nm}$ were observed for a solution of porphyrin. Emission $\left(\lambda_{\text {ex }}, 406 \mathrm{~nm}\right)$ and excitation spectra $\left(\lambda_{\text {em }}\right.$ was $\left.633 \mathrm{~nm}\right)$ have also been recorded, with significant broadening witnessed

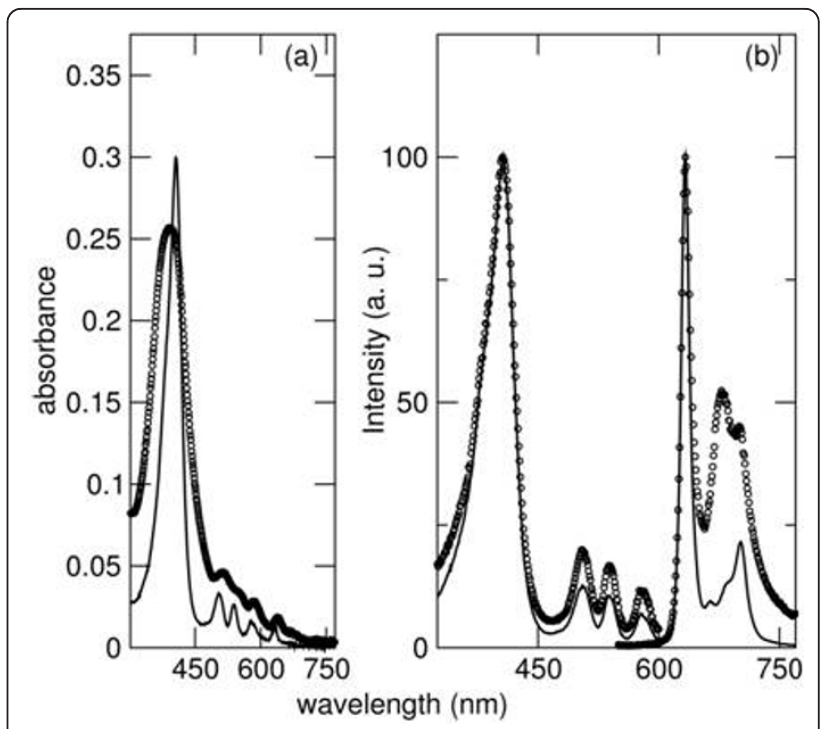

Figure 3 Optical characterisation of the PMNC: (a) Absorbance spectra of original protoporphyrin IX (solid line) $\left[1.57 \times 10^{-6} \mathrm{M}\right]$ and PMNC (dotted line) [100 $\mu$ PMNC in $3 \mathrm{ml} \mathrm{THF].} \mathrm{(b)} \mathrm{Normalised}$ emission and excitation spectra of original porphyrin (solid line) $\left[5.23 \times 10^{-7} \mathrm{M}\right]$ and PMNC (dotted line) $[100 \mu \mathrm{l}$ PMNC in $3 \mathrm{ml}$ with THF]. $\lambda_{\text {em }}=633 \mathrm{~nm}, \lambda_{\text {ex }}=406 \mathrm{~nm}$.

for the PMNC when compared to the original porphyrin. This can be attributed to the scattering of the incoming light by the PMNC suspension, but gives further indication of the binding of the porphyrin to the nanoparticle surface.

Dynamic Light Scattering (DLS) studies of silica coated magnetite nanoparticles have shown a very broad size distribution with an average hydrodynamic diameter of $131 \mathrm{~nm}$, due to aggregation of nanoparticles. However, silica coated porphyrin functionalised magnetic nanoparticles have demonstrated relatively narrow distribution with an average hydrodynamic diameter of 818 nm (Figure 4).

TEM images taken of the silica coated nanoparticles reveal the presence of a core-shell structure (Figure 5). The silane coating on the particles has an average thickness of $3 \mathrm{~nm}$ and the particles are found to aggregate in group of approximately ten particles. Upon reaction with the 3-aminopropyltriethoxysilane modified protoporphyrin, the coating thickness is found to slightly increase to $4 \mathrm{~nm}$.

Magnetisation measurements of original non-coated magnetite nanoparticles, silica coated magnetite nanoparticles and silica-coated porphyrin functionalised magnetite nanoparticles as expected, have shown a gradual reduction in saturation magnetisation values $\left(58.4 \mathrm{Am}^{2} /\right.$ $\mathrm{kg}$ for pristine magnetite nanoparticles, $35.2 \mathrm{Am}^{2} / \mathrm{kg}$ for silica coated magnetite nanoparticles and $27.5 \mathrm{Am}^{2} / \mathrm{kg}$ for the corresponding porphyrin conjugates) with an 

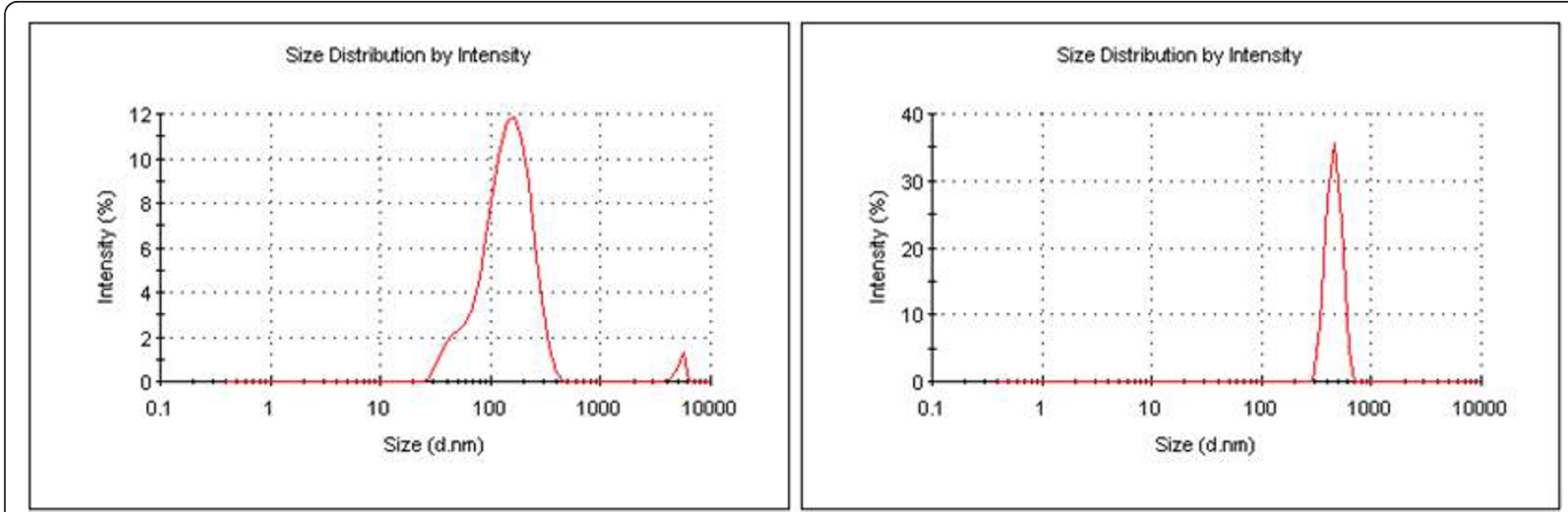

Figure 4 DLS results for suspensions of (a) silica coated magnetite nanoparticles and (b) silica-coated porphyrin functionalised magnetite nanoparticles.

increasing amount of non-magnetic material, i.e. silica and porphyrin conjugates (Figure 6).

The combination of both magnetic and fluorescent properties in one nanocomposite can provide additional benefits. For example, these nanocomposites could serve as multimodal assays for in vitro- and vivo-bioimaging applications such as MRI and fluorescence microscopy.
They can also be used as bimodal agents for anticancer therapy, encompassing photodynamic and hyperthermic capabilities. Fluorescent-magnetic nanocomposites may also be utilised as a multimodal diagnostic and therapeutic tool, which could be used, for example, to identify, diagnose and simultaneously treat various diseases. Other potential exciting applications of these

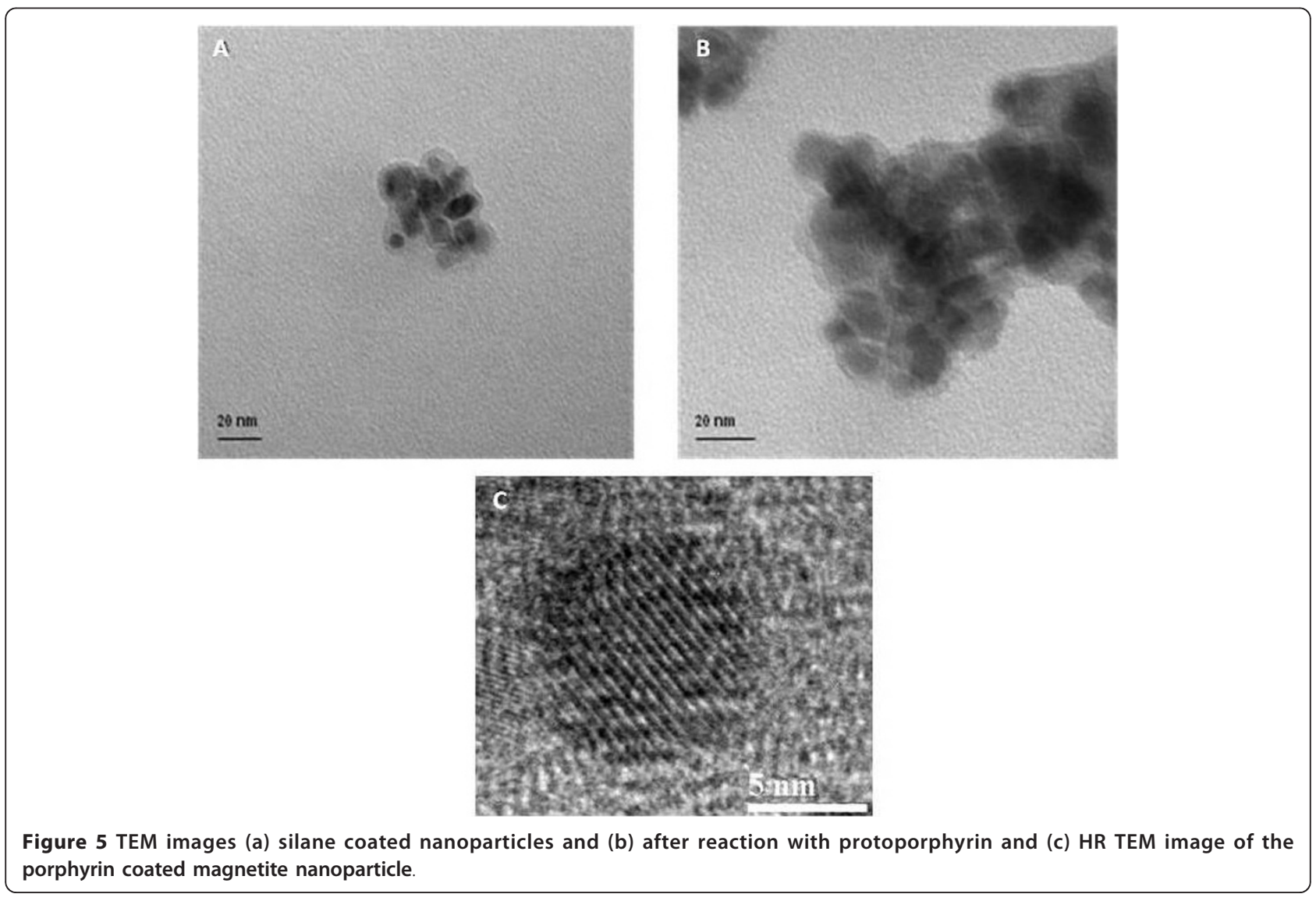



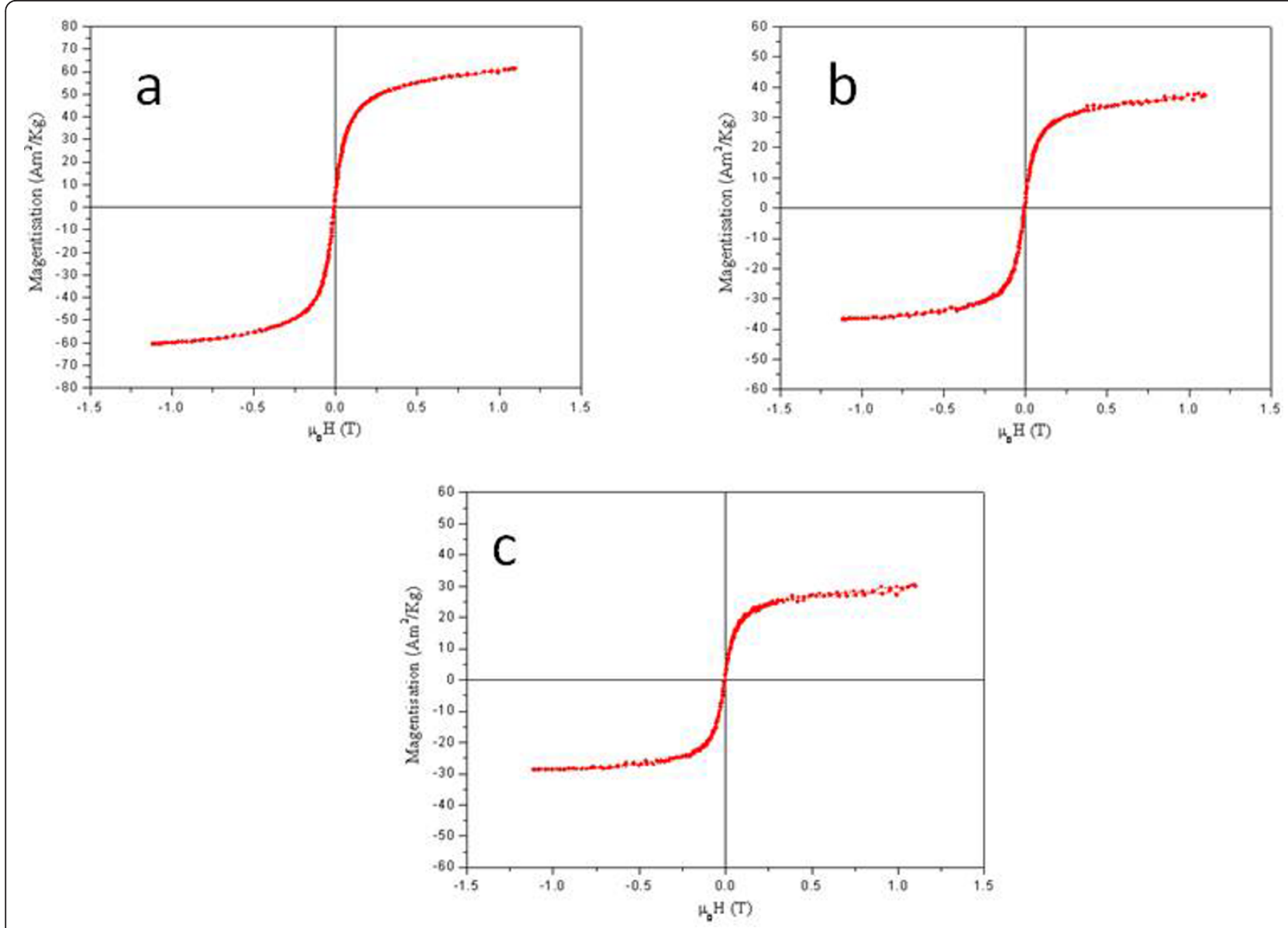

Figure 6 Magnetisation curves of original non-coated (a) magnetitite nanoparticles, (b) silica coated magnetite nanoparticles and (c) silica-coated porphyrin functionalised magnetite nanoparticles

nanocomposites include cell tracking, cytometry and magnetic separation, which could be easily controlled and monitored using fluorescent microscopy and MRI.

\section{Cell culture experiments}

Previously, the cytotoxic effects of poly(ethylene glycol)co-fumarate (PEGF)-coated magnetite nanoparticles and their capability for changing cell culture medium compositions have been investigated. The primary mouse connective tissue cells (L929) were used for this purpose. Toxicity levels and changes in the cell culture medium compositions were determined using the MTT assay and a UV/vis spectroscopy method, respectively. As compared to the conventional method, a more reliable method for determining the cytotoxicity of nanoparticles for in vitro applications is found [29]. It also has been demonstrated that the incorporation of anticancer drugs such paclitaxel into PLGA nanoparticles in nanoparticles strongly enhances the cytotoxic effect of the drug as compared to Taxol, this effect being more relevant for prolonged incubation times [30,31].
In our studies THP-1 (human acute monocytic leukaemia) cells were cultured in the presence of phorbol 12-myristate 13-acetate (PMA) for 3 days to initiate monocyte to macrophage differentiation. Half the volume of complete culture media was then replaced with serum free media to "starve" the cells, allowing for an enhanced up-take of the PMNC. Figure 7 shows a confocal image of a THP-1 cell after incubation with the PMNC for 3 hours. The particles are localised in the cytoplasm, as detected by confocal imaging, and the image is representative of the broader cell population.

During the experiments we have found that following an exposure time of only $482 \mathrm{~ms}$, the PMNC begins to photobleach, and after only 4 seconds, the fluorescence intensity has greatly decreased (Figure 8 ). This process is highly undesirable as it makes the generation, capture and interpretation of the image extremely difficult and does not allow for a full examination of the cells to determine precisely the nature of the nanocomposite localisation. 


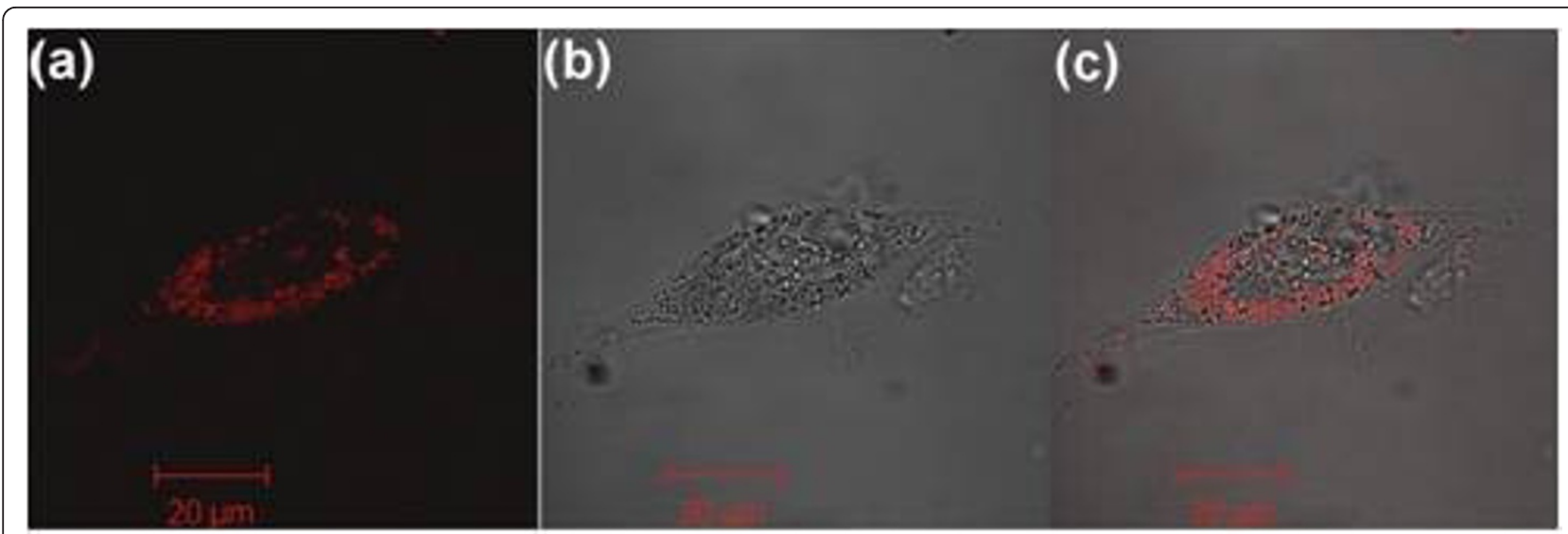

Figure 7 THP-1 cells incubated with the PMNC: THP-1 cells incubated with the PMNC for 3 hours. (a) confocal (b) bright field and (c) composite images of a THP-1 cell with internalised PMNC ( $\left.\lambda_{\text {ex }}=540 \mathrm{~nm}\right)$.

In an effort to alleviate the photobleaching, $\beta$-mercaptoethanol ( $\beta$-ME) was employed to counteract this problem, and was added once the cells were fixed. Control experiments performed with THP-1 cells in the presence of $\beta$-ME show that no deleterious effects are witnessed and the cells retain their size, shape and membrane integrity (Figure 9). Addition of $\beta$-ME to cells cultured with the PMNC prevented this photobleaching effect and resulted in a stronger fluorescence signal compared to those without $\beta$-ME (see Figures 9 and 10). Following the same cell preparation and coincubation times, we can clearly see not only an increased resistance to photobleaching, but the addition of $\beta-\mathrm{ME}$ also resulted in an enhanced and extended fluorescence emission. This improved photostability is due to the $\beta$-ME acting as a scavenger for singlet oxygen, which is traditionally attributed to the photobleaching of porphyrin based dyes.
To further exemplify the enhancement in fluorescent emission intensity due to the presence of the $\beta$-ME, pseudocoloured images of the cells were generated (Figure 10). The pseudocoloured images reflect the integrated fluorescence intensity levels across the cytoplasmic and nuclear compartments of the THP-1 cells. Background fluorescence appears blue and predominates for those cells without any nanocomposite added (panels $10 \mathrm{c}$ and d) but also for cells cultured with the PMNC alone (panel 10 a). A dramatic change is witnessed upon addition of the $\beta$-ME (panel $10 \mathrm{~b}$ ). The PMNC is no longer quenched so dramatically and readily emits with substantial emission increases recorded after 4 seconds.

To verify that the increased emission is due to the PMNC and not as a result of increased cellular autofluorescence, control experiments were also conducted. Panels $10 \mathrm{c}$ and $\mathrm{d}$ show untreated and $\beta$-ME treated
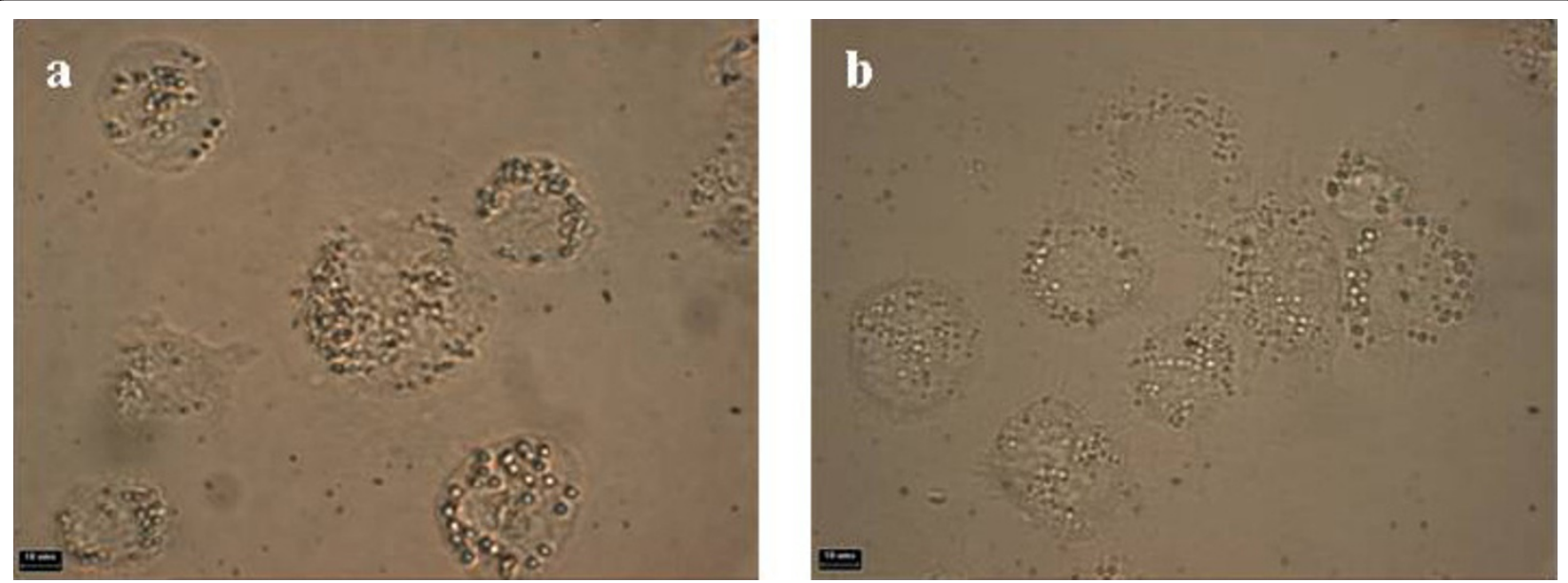

Figure 8 Transmitted light microscopic images of (a) untreated THP-1 cells and (b) THP-1 cells in the presence of $\beta$-ME. Note scale bar equals $10 \mu \mathrm{m}$. No deleterious effects to the cell size, shape or membrane integrity are noted. 


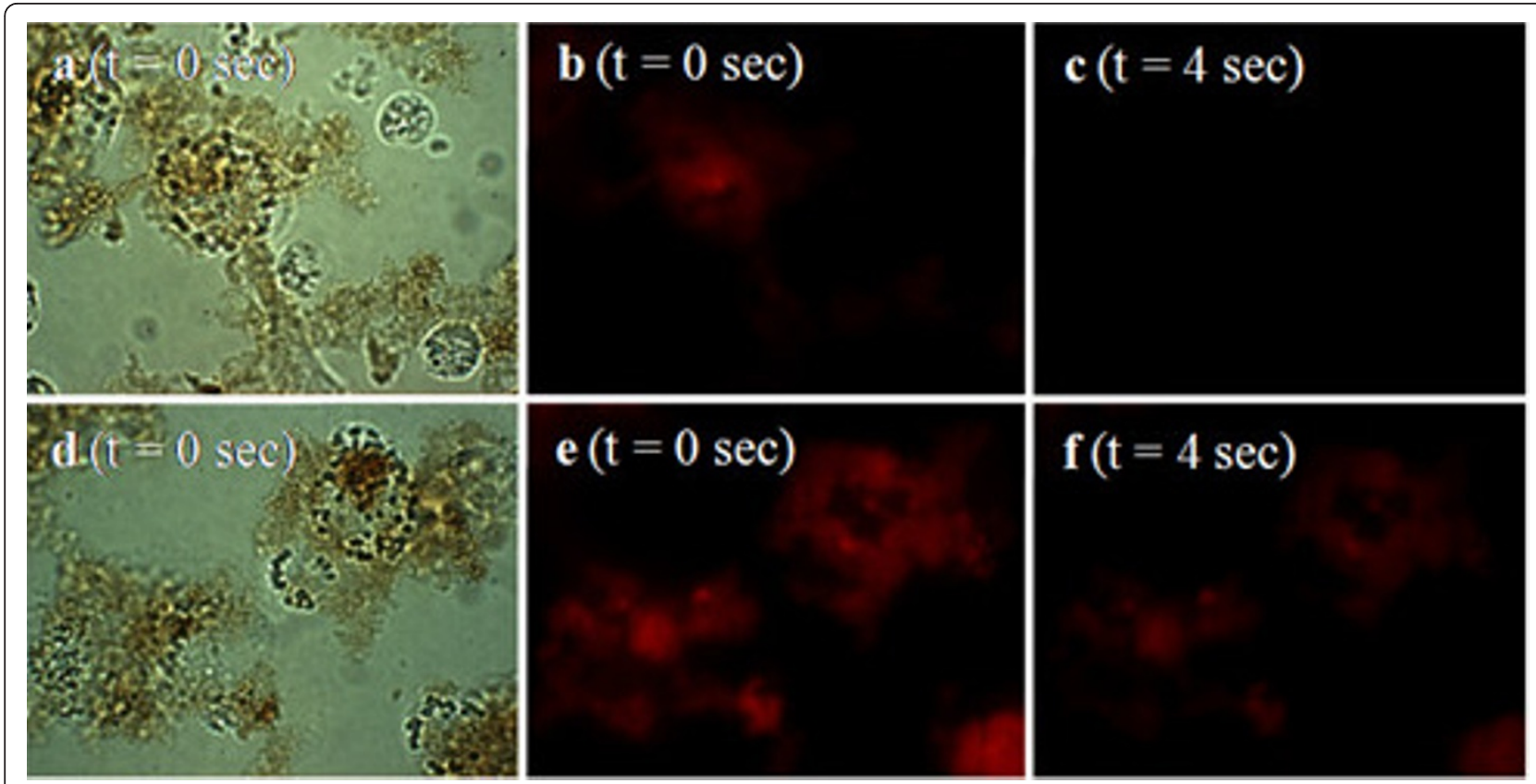

Figure 9 Evaluation of PMNC emission intensities: comparison of the PMNC emission intensity when incubated with THP-1 cells with (bottom panel) and without (top panel) $\beta$-ME. (a) Bright field and (b, c) fluorescence images of the PMNC and the THP-1 cells without $\beta$-ME (d) Bright field and $(e, f)$ fluorescence images of the PMNC and the THP-1 cells with $\beta$-ME. Note: $(a, b, d, e)$ images taken at $t=0$ seconds, (c, $f$ ) taken at $\mathrm{t}=4$ seconds, exposure time for each image is $482 \mathrm{~ms}$ and $\left(\lambda_{\text {ex }}=540 \mathrm{~nm}\right)$.

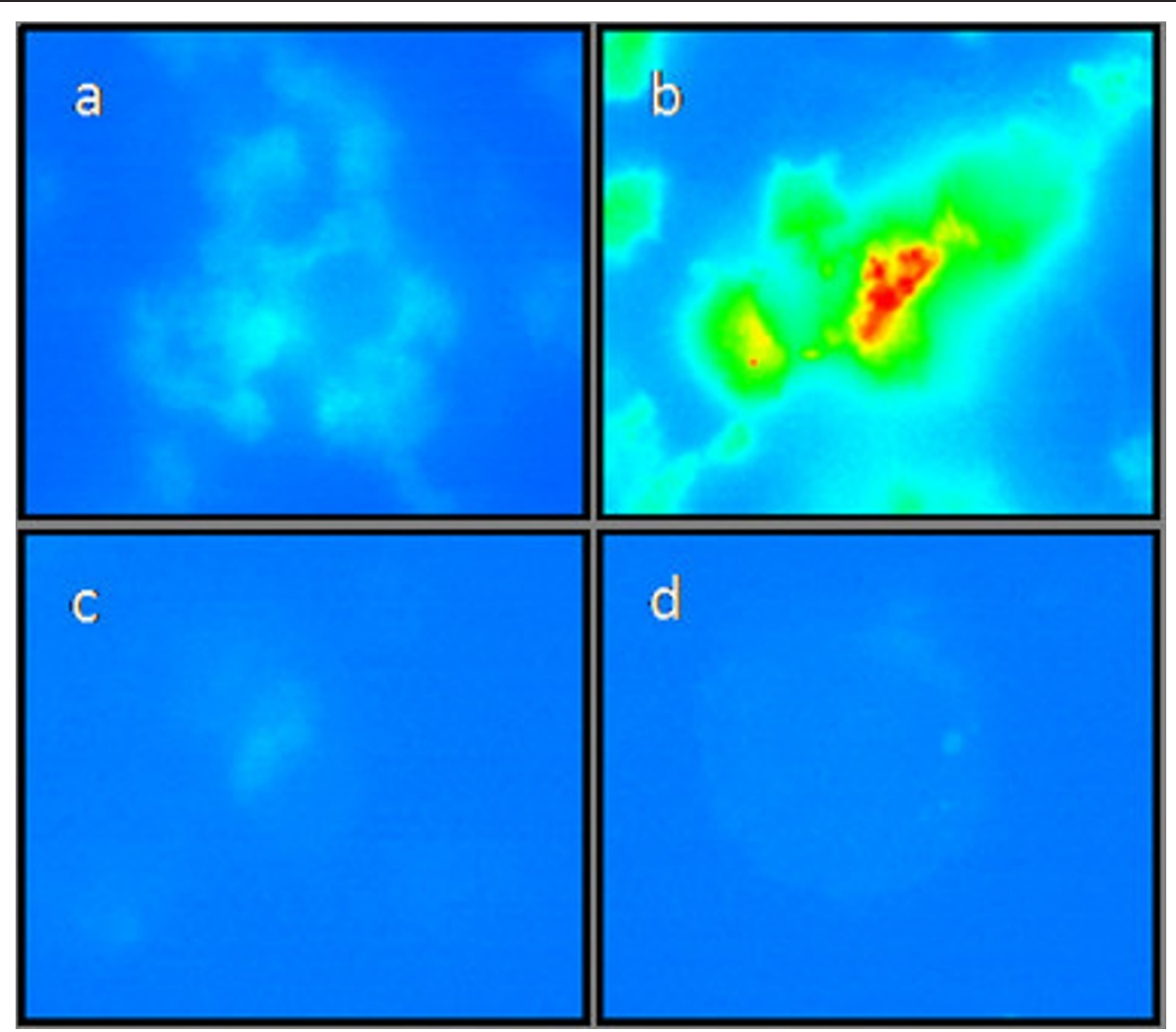

Figure 10 Pseudocoloured fluorescence images: pseudocolored images of (a) THP-1 cells incubated with the PMNC (b) THP-1 cells incubated with PMNC in the presence of $\beta$-ME (c) untreated THP-1 cells and (d) cells in the presence of $\beta$-ME alone. Transition colour from blue to red indicates an increase in fluorescence intensity. 
THP-1 cells respectively and clearly illustrate that the level of background fluorescence remains constant throughout the experiment. This proves that autofluorescence does not contribute to the enhanced levels of emission witnessed for those cells cultured with the PMNC in the presence of $\beta$-ME.

In order to probe the maximum fluorescence intensity of the PMNC as a function of excitation wavelength and also to monitor the fluorescence intensity across the cell compartments, a series of fluorescence images were recorded over varying wavelengths together with emission spectral mapping of the cell. Cells were cultured with the PMNC with and without the presence of $\beta$ ME. Lambda scans recorded of cells cultured without $\beta$ ME show a noted decrease in brightness and the combined image is noticeably lower in fluorescence intensity. This is shown quantitatively in the fluorescence emission spectra, which show an almost $20 \%$ decrease in fluorescence intensity (Figures 11 and 12).

Finally, to compare the results a series of similar control experiments have been performed on "non-starved" THP-1 cells, which were incubated with serum free media. Confocal and composite images of the cells incubated with fluorescent magnetic nanoparticles have been taken at different periods of time $24 \mathrm{hrs}, 48 \mathrm{hrs}$ and 5 days (Figures 13, 14, 15 and 16). The results have demonstrated that there was no cellular uptake of the fluorescent nanocomposites but only binding of the PMNC to the outer cell membranes.

\section{Conclusion}

In summary, we have successfully synthesised a new two-in-one magnetic-fluorescent nanocomposite. Initial co-incubation experiments performed with THP-1 macrophage cells in the presence of the PMNC showed a distinct photobleaching of the porphyrin upon exposure to light under a fluorescent microscope. This bleaching was counteracted by the addition of $\beta-\mathrm{ME}$ which resulted not only in increased fluorescence intensity levels, but also allowed for enhanced imaging and increased exposure times of the PMNC in a cellular environment. This was further corroborated by pseudofluorescent images which show how $\beta$-ME visibly enhances the emission intensity. Furthermore, no deleterious effects to the cells were witnessed upon co-incubation with $\beta$-ME alone and no increases in background fluorescence were recorded. We believe that this research should present an interest for further development of and new multimodal nanoparticulate agents for in vitro biological imaging.

\section{Materials and methods}

Synthesis

\section{Synthesis of nanoparticles and coating with silica}

Magnetite nanoparticles were prepared according to the previously reported coprecipitation method. Stock solutions of $25 \mathrm{~mL}$ of each of $1 \mathrm{M} \mathrm{FeCl}_{3} \cdot 6 \mathrm{H}_{2} \mathrm{O}(6.56 \mathrm{~g}$, $0.024 \mathrm{~mol}), 0.5 \mathrm{M} \mathrm{FeCl}_{2} .4 \mathrm{H}_{2} \mathrm{O}$ (2.48 g, $\left.0.012 \mathrm{~mol}\right)$, and $0.4 \mathrm{M} \mathrm{HCl}$ were made up with Millipore water. $\mathrm{NaOH}$

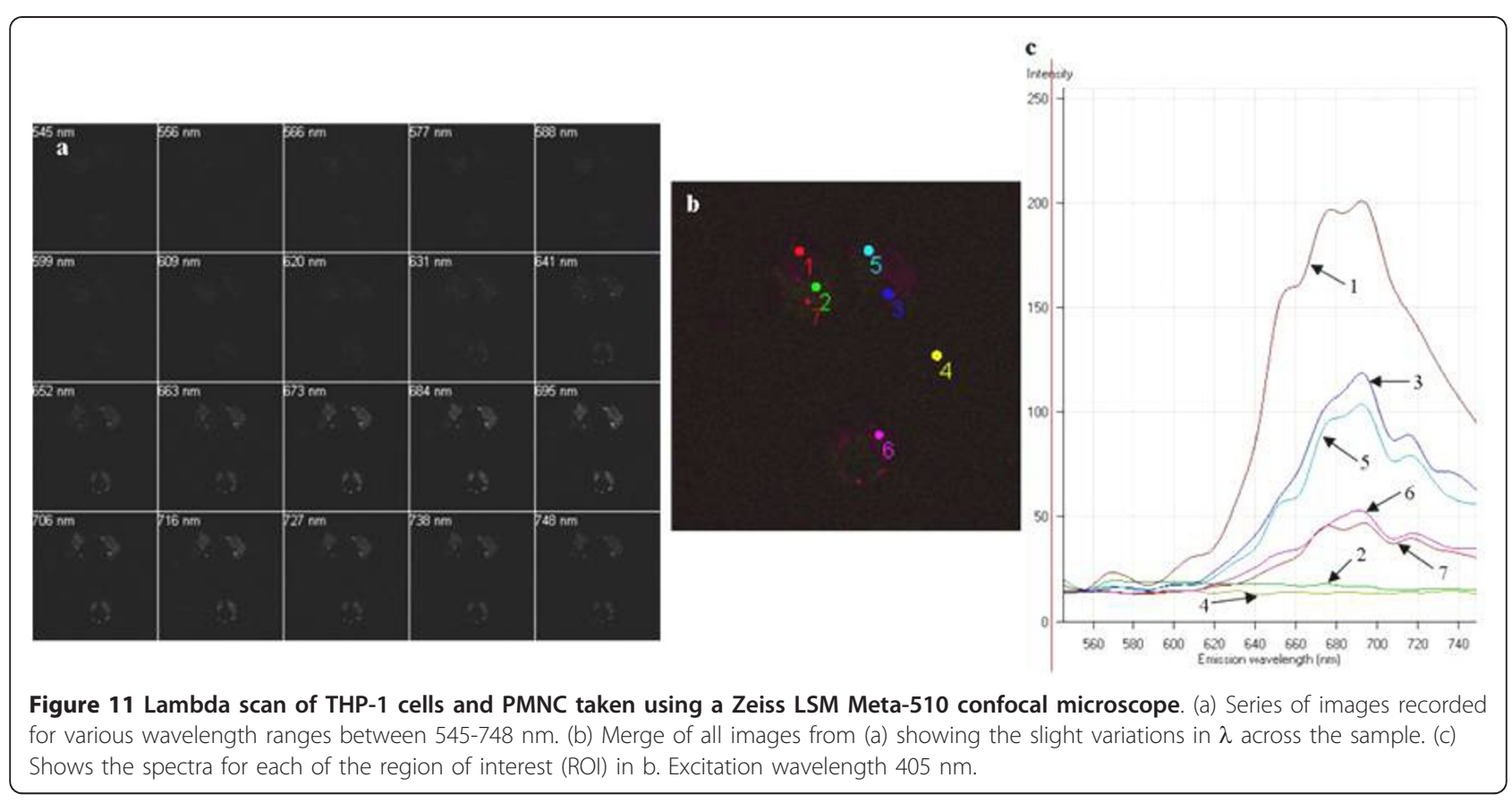




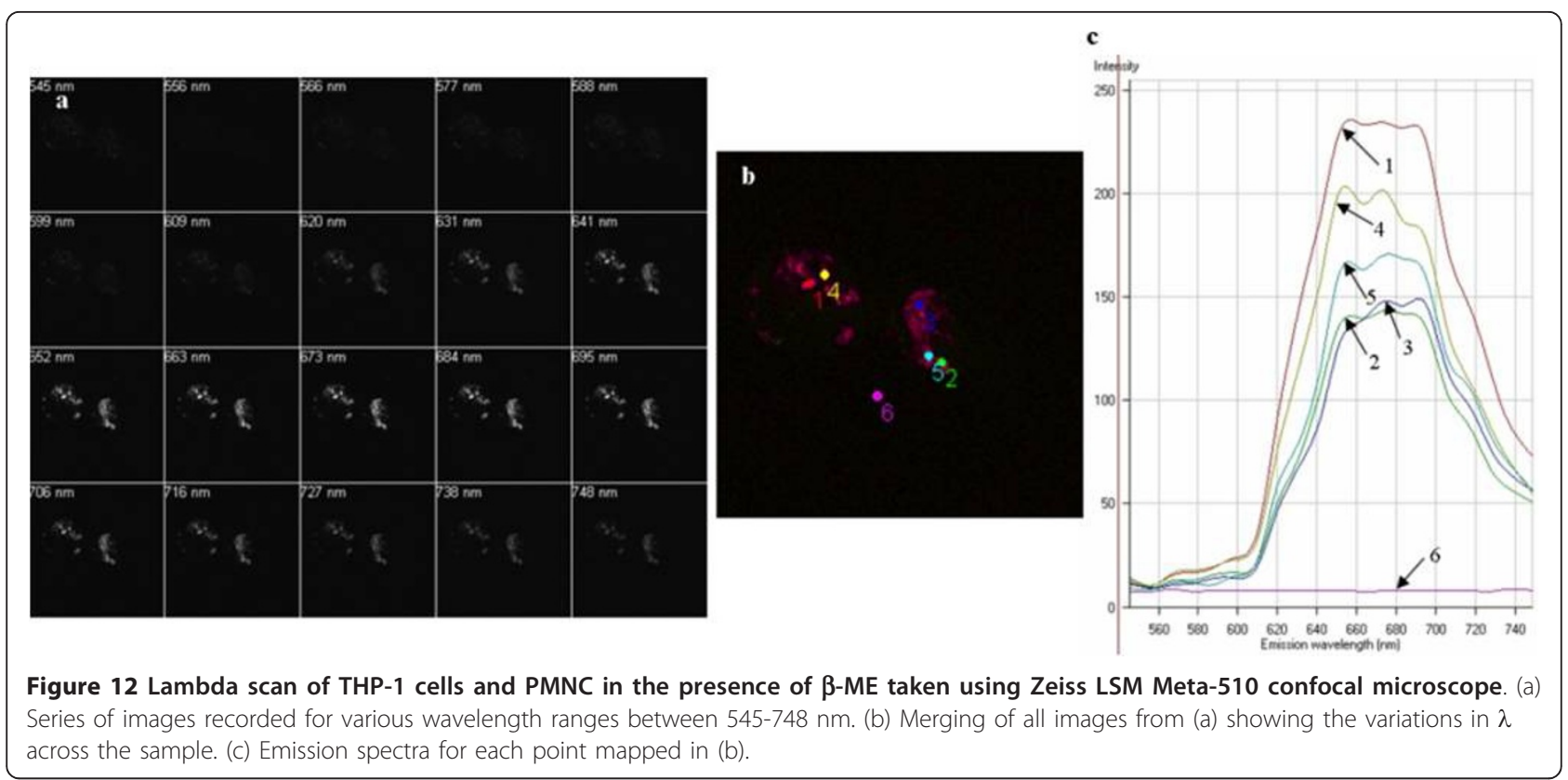

solution $(0.5 \mathrm{M}, 250 \mathrm{~mL})$ was heated to $80^{\circ} \mathrm{C}$ and the iron solution was added dropwise. After one hour of stirring (at $1200 \mathrm{rpm}$ ) with heat, the black magnetic nanoparticles were washed with Millipore water $(5 \times 20$ $\mathrm{mL})$ until neutral. A sample of the nanoparticles $(1 \mathrm{~g})$ was dispersed in tetramethylammonium hydroxide (30 $\mathrm{mL}$ ) and made up to $570 \mathrm{~mL}$ with Millipore water. $0.58 \%$ activated sodium silicate $(430 \mathrm{~mL})$ was added to the nanoparticle suspension. The sodium silicate was activated by passing through a regenerated cation exchange resin. After two hours stirring, the magnetic fluid was transferred into dialysis tubing and dialysed against Millipore water brought to $\mathrm{pH} 10$ by the addition of tetramethylammonium hydroxide. The dialysis tubing was prepared by boiling tubing of the required length in $2 \%(\mathrm{w} / \mathrm{v})$ sodium bicarbonate $(100 \mathrm{~mL})$ and 1 mM EDTA $(100 \mathrm{~mL})$ at $\mathrm{pH} 8.0$ for ten minutes. The tubing was rinsed with Millipore water then boiled for ten minutes in $1 \mathrm{mM}$ EDTA followed by Millipore water rinsing. After 24 hour dialysis, the solution was brought to $\mathrm{pH} 8.0$ by the addition of dilute $\mathrm{HCl}$. The particles were washed and finally dried under vacuum.

Modification of protoporphyrin and attachment to magnetic nanoparticles

Protoporphyrin IX (0.1 g; $0.177 \mathrm{mmol})$ was dissolved in dry THF (20 mL). $N$-(3-Dimethylaminopropyl)- $N$-ethylcarbodiimide $(0.17 \mathrm{~g} ; 0.887 \mathrm{mmol})$ was added to' the stirring deep red solution and the reaction mixture was stirred (at $1200 \mathrm{rpm}$ ) for 3 hours at $0^{\circ} \mathrm{C}$. The reaction was carried out in the dark to prevent any possible
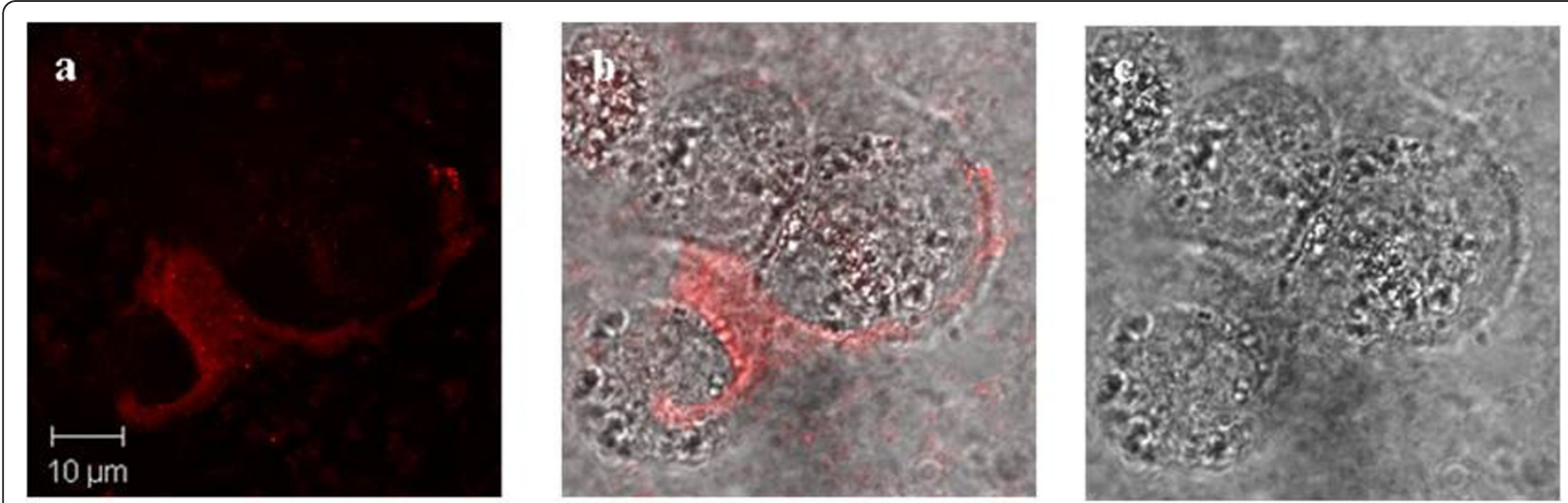

Figure 13 (a) Confocal, (b) composite and (c) bright field images showing the localization patterns of the PMNC in live THP-1 macrophage cells following a $\mathbf{2 4}$ hour co-incubation period. Panel (a) shows the clear fluorescence labelling of the outer cell membranes by the nanoparticles. The PMNC did not penetrate the cell membrane as these cells were not incubated with serum free media. 

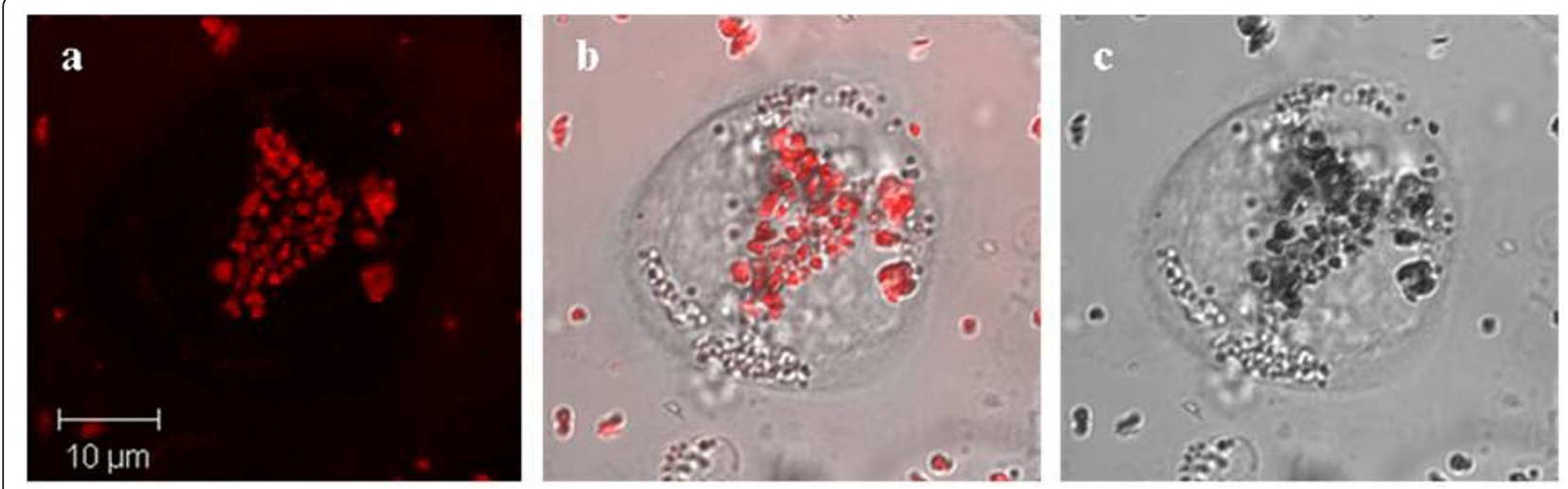

Figure 14 (a) Confocal, (b) composite and (c) bright field images of THP-1 macrophage exposed to the PMNC for 24 hours. Cells were incubated with serum free media for 2 hours.

photobleaching of the porphryin. 3-Aminopropyltriethoxysilane $(83 \mu \mathrm{L} ; 0.355 \mathrm{mmol})$ in $2 \mathrm{~mL}$ dry THF was added to the porphyrin solution at $0^{\circ} \mathrm{C}$. The reaction mixture was brought to room temperature and allowed to react overnight. Silica coated magnetite nanoparticles $(0.1 \mathrm{~g})$ were added to the reaction vessel with triethylamine $(300 \mu \mathrm{L})$ and allowed to react for 24 hours. The mixture was centrifuged and the particles were washed with bench THF $(5 \times 40 \mathrm{~mL})$ to remove any un-reacted porphyrin or unwanted side-products. The particles of PMNC were finally washed with water. Elemental analysis, found: $\mathrm{C}-9.31, \mathrm{H}-1.21, \mathrm{~N}-1.51$.

\section{Tissue culture}

THP-1 cells, a human acute monocytic leukaemia cell line, were obtained from the American Type Culture Collection (ATCC, LGC Promochem, U.K.). Cells were cultured in RPMI 1640 medium with 25 mM HEPES (Gibco, Invitrogen Ltd., Ireland), supplemented with heat-inactivated foetal bovine serum (FBS) (9\%), 200 $\mathrm{mM} / \mathrm{ml} \mathrm{L}$-glutamine $(0.9 \%, 1.8 \mathrm{mM} / \mathrm{ml}), 10,000 \mathrm{U} / \mathrm{ml}$ penicillin $(0.9 \%, 90 \mathrm{U} / \mathrm{ml})$, and $10 \mathrm{mg} / \mathrm{ml}$ streptomycin $(0.9 \%, 0.09 \mathrm{mg} / \mathrm{ml})$ at $37^{\circ} \mathrm{C}$ and $5 \% \mathrm{CO}_{2}$ content.

\section{Cell assays}

THP-1 cells were seeded into an 8 -well chamber slide, with a final concentration of $2 \times 10^{4}$ cells per well. To induce monocyte to macrophage differentiation, THP-1 cells were cultured in $100 \mathrm{ng} / \mathrm{ml}$ phorbol 12-myristate 13 -acetate (PMA) for 3 days at $37^{\circ} \mathrm{C}$ in $5 \% \mathrm{CO}_{2}$. Half the volume of media was then replaced by serum free media (RPMI 1640 with 25 mM HEPES) and the cells were incubated for 2 hours at $37^{\circ} \mathrm{C}$ in $5 \% \mathrm{CO}_{2}$. The PMNC was then added at a final concentration of 0.25 $\mathrm{mg} / \mathrm{ml}$. To another well, $\beta$-mercaptoethanol $\beta$-ME was added. A control experiment with the Protoporphyrin IX dissolved in mixture of water and tetrahydrofuran (THF) was carried out in parallel using the same conditions, with a final porphyrin concentration of $0.119 \mathrm{mg} /$ ml. Fluorescence images were recorded using a Nikon TE3000 inverted microscope. Confocal imges were collected using a $63 \times$ oil immersion objective, laser
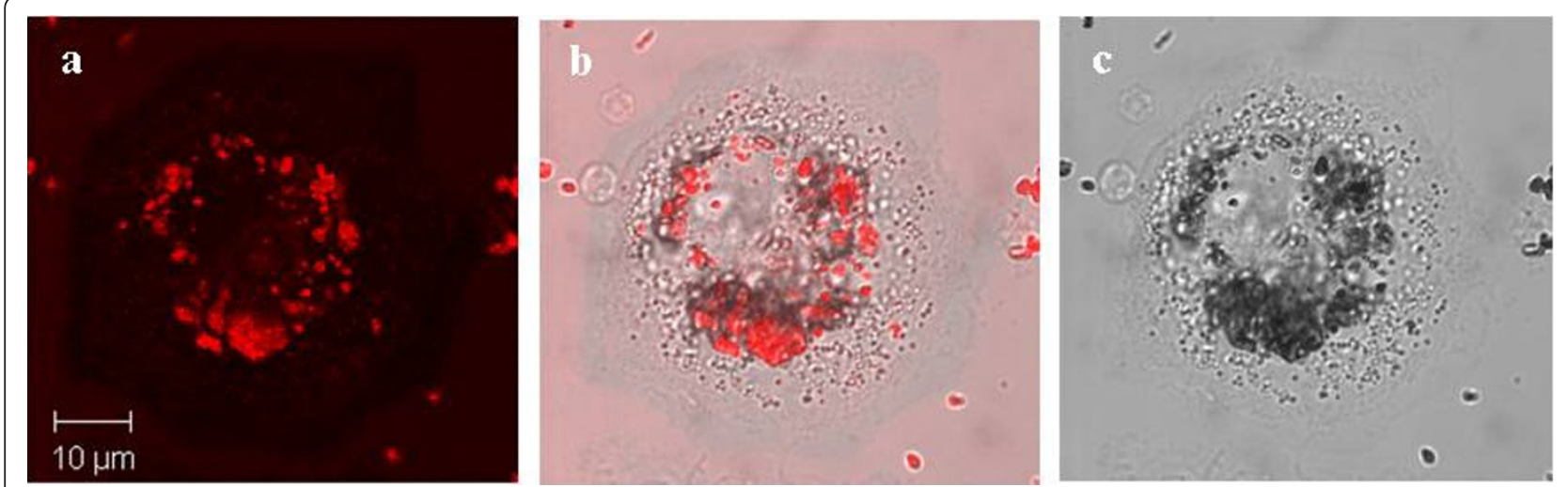

Figure 15 (a) Confocal, (b) composite and (c) bright field images of THP-1 macrophage cells exposed to the PMNC for 48 hours. Cells were incubated with serum free media for 2 hours. 

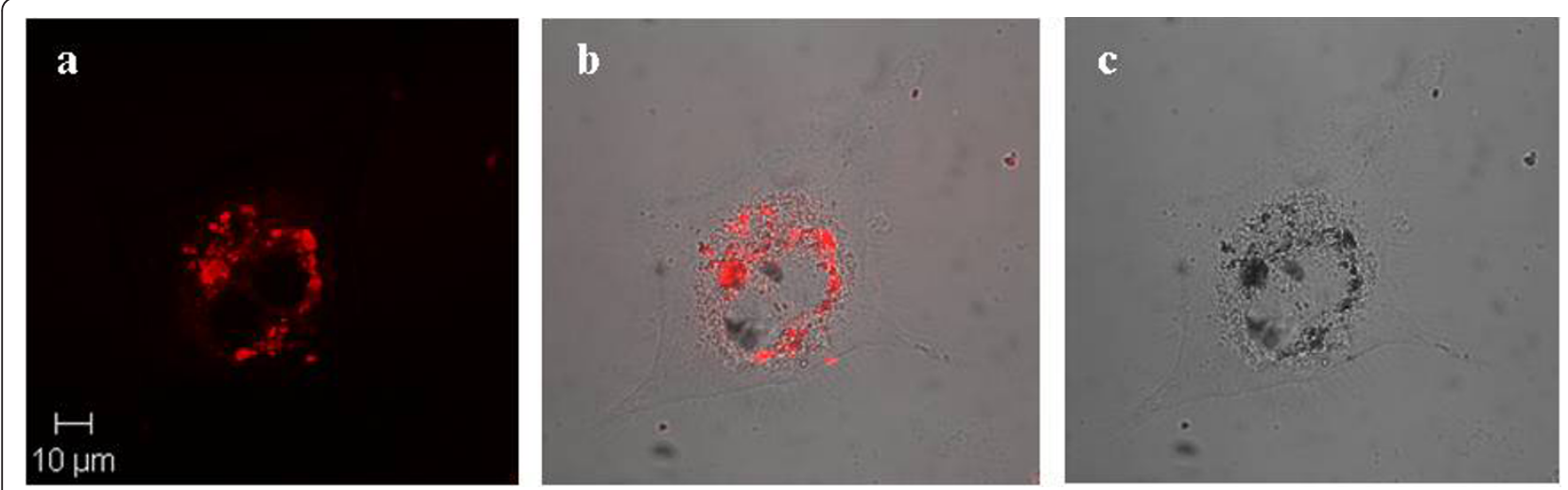

Figure 16 (a) Confocal, (b) composite and (c) bright field images of THP-1 macrophage cells exposed to the PMNC for 5 days. Cells were incubated with serum free media for 2 hours.

excitation $561 \mathrm{~nm}$ and LP $575 \mathrm{~nm}$ filter on a Zeiss LSM Meta-510 confocal microscope.

\section{Spectroscopy}

UV-Vis absorption spectra were recorded using a Cary 50 UV-Vis spectrophotometer. Fluorescence measurements were performed on a Cary Eclipse spectrophotometer. FT-IR spectra were recorded $\mathrm{KBr}$ using a Perkin Elmer Spectrum One FT-IR spectrophotometer. TEM images were taken on a Hitachi $\mathrm{H}-7000$ at a beam voltage of $100 \mathrm{kV}$.

\section{Abbreviations}

AC: alternating current; 3-APTES: 3-aminopropyltriethoxysilane; $\beta$-ME: $\beta$ mercaptoethanol; DLS: Dynamic Light Scattering; EDTA: ethylenediamine tetraacetic acid; EDCl: 1-ethyl-3-(3-dimethylaminopropyl carbodiimide); HEPES: 4-(2-hydroxyethyl)-1-piperazineethanesulfonic acid; THP-1 cells: human acute monocytic leukaemia cells; PMA: phorbol 12-myristate 13acetate; PMNC: porphyrin-magnetite nanocomposite; RPMI: Roswell Park Memorial Institute Medium; TEM: Transmission electron microscopy; THF: tetrahydrofuran; TMAH: tetramethylammonium hydroxide; UV-vis: Ultra-violet visible.

\section{Acknowledgements}

We would like to thank Science Foundation Ireland (SFI) and the Health Research Board of Ireland for financial support.

\section{Author details}

${ }^{1}$ School of Chemistry, Trinity College Dublin, College Green, Dublin 2, Ireland. ${ }^{2}$ Department of Clinical Medicine, Trinity Centre for Health Sciences, Trinity College Dublin, St. James's Hospital, Dublin 8, Ireland. ${ }^{3}$ School of Physical Sciences, University of Kent, Canterbury, CT2 7NH.

\section{Authors' contributions}

MN and JC performed all cellular experiments. MN and SAC performed all nanoparticle synthesis and characterisation, and wrote the manuscript with SB and YKG. MN and JC conducted confocal imaging. YKG and $\mathrm{YV}$ designed the overall project and helped with data and manuscript revision. All authors read and approved the final manuscript.

\section{Competing interests}

The authors declare that they have no competing interests.

Received: 18 August 2009 Accepted: 8 April 2011

Published: 8 April 2011

\section{References}

1. Pankhurst QA, Connolly J, Jones SK, Dobson J: Applications of magnetic nanoparticles in biomedicine. Journal of Physics D: Applied Physics 2003, R167.

2. Bergemann C, Muller-Schulte D, Oster J, a Brassard L, Lubbe AS: Magnetic ion-exchange nano- and microparticles for medical, biochemical and molecular biological applications. J Magn Magn Mater 1999, 194:45-52.

3. Byrne SJ, Corr SA, Gun'ko YK, Kelly JM, Brougham DF, Ghosh S: Magnetic nanoparticle assemblies on denatured DNA show unusual magnetic relaxivity and potential applications for MRI. Chemical Communications 2004, 2560-2561.

4. Wan J, Cai W, Meng X, Liu E: Monodisperse water-soluble magnetite nanoparticles prepared by polyol process for high-performance magnetic resonance imaging. Chemical Communications 2007, 5004-5006.

5. Corr SA, Byrne SJ, Tekoriute R, Meledandri CJ, Brougham DF, Lynch M, Kerskens C, O'Dwyer L, Gun'ko YK: Linear Assemblies of Magnetic Nanoparticles as MRI Contrast Agents. Journal of the American Chemical Society 2008, 130:4214-4215.

6. Corr SA, Gunâ€TMko YK, Tekoriute R, Meledandri CJ, Brougham DF: Poly (sodium-4-styrene)sulfonate-Iron Oxide Nanocomposite Dispersions with Controlled Magnetic Resonance Properties. The Journal of Physical Chemistry C 2008, 112:13324-13327.

7. Samanta B, Yan H, Fischer NO, Shi J, Jerry DJ, Rotello VM: Proteinpassivated Fe3O4 nanoparticles: low toxicity and rapid heating for thermal therapy. Journal of Materials Chemistry 2008, 18:1204-1208.

8. BabincovÃ $\tilde{A}_{i}$ M, Leszczynska D, Sourivong P, Babinec P: Selective treatment of neoplastic cells using ferritin-mediated electromagnetic hyperthermia. Medical hypotheses 2000, 54:177-179.

9. Guo M, Yan Y, Zhang H, Yan H, Cao Y, Liu K, Wan S, Huang J, Yue W: Magnetic and $\mathrm{pH}$-responsive nanocarriers with multilayer core-shell architecture for anticancer drug delivery. Journal of Materials Chemistry 2008, 18:5104-5112.

10. Landmark KJ, DiMaggio S, Ward J, Kelly C, Vogt S, Hong S, Kotlyar A, Myc A, Thomas TP, Penner-Hahn JE, et al: Synthesis, Characterization, and in Vitro Testing of Superparamagnetic Iron Oxide Nanoparticles Targeted Using Folic Acid-Conjugated Dendrimers. ACS Nano 2008, 2:773-783.

11. Ji-Ho P, Geoffrey von M, Lianglin Z, Michael PS, Erkki R, Sangeeta NB, Michael JS: Magnetic Iron Oxide Nanoworms for Tumor Targeting and Imaging. Advanced Materials 2008, 20:1630-1635.

12. Quarta A, Di Corato R, Manna L, Argentiere S, Cingolani R, Barbarella G, Pellegrino T: Multifunctional Nanostructures Based on Inorganic Nanoparticles and Oligothiophenes and Their Exploitation for Cellular Studies. Journal of the American Chemical Society 2008, 130:10545-10555.

13. Teodor E, Litescu SC, Petcu C, Mihalache M, Somoghi R: Nanostructured Biomaterials with Controlled Properties Synthesis and Characterization. Nanoscale Research Letters 2009, 4:544-549.

14. Corr S, Rakovich Y, Gun'ko Y: Multifunctional Magnetic-fluorescent Nanocomposites for Biomedical Applications. Nanoscale Research Letters 2008, 3:87-104 
15. Salgueiriño-Maceira V, Correa-Duarte MA: Increasing the Complexity of Magnetic Core/Shell Structured Nanocomposites for Biological Applications. Advanced Materials 2007, 19:4131-4144.

16. Xiao Q, Xiao C: Preparation and Characterization of Silica-Coated Magnetic-Fluorescent Bifunctional Microspheres. Nanoscale Research Letters 2009, 4:1078-1084.

17. Gallagher JJ, Tekoriute R, O'Reilly JA, Kerskens C, Gun'ko YK, Lynch M: Bimodal magnetic-fluorescent nanostructures for biomedical applications. Journal of Materials Chemistry 2009, 19:4081-4084.

18. Prina-Mello A, Whelan AM, Atzberger A, McCarthy JE, Byrne F, Davies GL, Coey JMD, Volkov Y, Gun'ko YK: Comparative Flow Cytometric Analysis of Immunofunctionalized Nanowire and Nanoparticle Signatures. Small 6:247-255.

19. Ge Y, Zhang Y, He S, Nie F, Teng G, Gu N: Fluorescence Modified Chitosan-Coated Magnetic Nanoparticles for High-Efficient Cellular Imaging. Nanoscale Research Letters 2009, 4:287-295.

20. Gole A, Agarwal N, Nagaria P, Wyatt MD, Murphy CJ: One-pot synthesis of silica-coated magnetic plasmonic tracer nanoparticles. Chemical Communications 2008, 6140-6142.

21. Ren C, Li J, Liu Q, Ren J, Chen X, Hu Z, Xue D: Synthesis of Organic DyeImpregnated Silica Shell-Coated Iron Oxide Nanoparticles by a New Method. Nanoscale Research Letters 2008, 3:496-501.

22. Corr SA, Byrne AO, Gun'ko YK, Ghosh S, Brougham DF, Mitchell S, Volkov Y, Prina-Mello A: Magnetic-fluorescent nanocomposites for biomedical multitasking. Chemical Communications 2006, 43:4474-4476.

23. Mahmoudi M, Shokrgozar MA, Simchi A, Imani M, Milani AS, Stroeve $P$, Vali H, Hafeli UO, Bonakdar S: Multiphysics Flow Modeling and in Vitro Toxicity of Iron Oxide Nanoparticles Coated with Poly(vinyl alcohol) (vol 113C, pg 2323, 2009). Journal of Physical Chemistry C 2009, 113:17274-17274.

24. Moroz P, Jones SK, Gray BN: Magnetically mediated hyperthermia: current status and future directions. International Journal of Hyperthermia 2002, 18:267-284.

25. Petri-Fink $A$, Chastellain $M$, Juillerat-Jeanneret $L$, Ferrari A, Hofmann $H$ : Development of functionalized superparamagnetic iron oxide nanoparticles for interaction with human cancer cells. Biomaterials 2005, 26:2685-2694.

26. Massart $\mathrm{R}$ : Preparation of aqueous magnetic liquids in alkaline and acidic media. IEEE Trans Magn 1981, 17:1247-1248.

27. Mahmoudi M, Simchi A, Imani M, Milani AS, Stroeve P: Optimal Design and Characterization of Superparamagnetic Iron Oxide Nanoparticles Coated with Polyvinyl Alcohol for Targeted Delivery and Imaging. Journal of Physical Chemistry B 2008, 112:14470-14481.

28. Philipse AP, van Bruggen MPB, Pathmamanoharan C: Magnetic silica dispersions: preparation and stability of surface-modified silica particles with a magnetic core. Langmuir 1994, 10:92-99.

29. Mahmoudi M, Simchi A, Imani M, Milani AS, Stroeve P: An in vitro study of bare and poly(ethylene glycol)-co-fumarate-coated superparamagnetic iron oxide nanoparticles: a new toxicity identification procedure. Nanotechnology 2009, 20

30. Fonseca C, Simoes S, Gaspar R: Paclitaxel-loaded PLGA nanoparticles: preparation, physicochemical characterization and in vitro anti-tumoral activity. Journal of Controlled Release 2002, 83:273-286.

31. Hosseinkhani H, Aoyama T, Ogawa O, Tabata Y: Ultrasound enhancement of in vitro transfection of plasmid DNA by a cationized gelatin. Journal of Drug Targeting 2002, 10:193-204.

doi:10.1186/1477-3155-9-13

Cite this article as: Nowostawska et al:: Porphyrin-magnetite nanoconjugates for biological imaging. Journal of Nanobiotechnology 2011 9:13.

\section{Submit your next manuscript to BioMed Central and take full advantage of:}

- Convenient online submission

- Thorough peer review

- No space constraints or color figure charges

- Immediate publication on acceptance

- Inclusion in PubMed, CAS, Scopus and Google Scholar

- Research which is freely available for redistribution

Submit your manuscript at www.biomedcentral.com/submit
Biomed Central 